\title{
Long-term quality of life in cervical dystonia after treatment with abobotulinum toxin A: a 2-year prospective study
}

This article was published in the following Dove Press journal:

Neuropsychiatric Disease and Treatment

\author{
Subsai Kongsaengdao $0^{1,2}$ \\ Narong Maneeton ${ }^{3}$ \\ Benchalak Maneeton ${ }^{3}$ \\ 'Division of Neurology, Department \\ of Medicine, Rajavithi Hospital, \\ Department of Medical Services, \\ Public Health Ministry, Bangkok, \\ Thailand; ${ }^{2}$ Department of Medicine, \\ College of Medicine, Rangsit \\ University, Bangkok, Thailand; \\ ${ }^{3}$ Department of Psychiatry, Faculty \\ of Medicine, Chiang Mai University, \\ Chiang Mai, Thailand
}

Background: The short-term quality of life (QoL) in cervical dystonia (CD) after treating with abobotulinum toxin A (Abo-BTX A) and neubotulinum toxin A (Neu-BTX A) have been studied in Thai CD patients.However; the long-term study has not been published.

Objective: The aim of the present study was to determine long-term improvement of the health-related quality of life (HRQoL) after eight injections of Abo-BTX A over 2 years in CD patients.

Patients and methods: A 2-year prospective study on the QoL of CD patients, as measured by HRQoL, before and after receiving eight injections of Abo-BTX A at 3-month intervals over a 2-year treatment period was performed. The disease-specific HRQoL was assessed before and after the treatment by using the Cervical Dystonia Impact Profile-58 (CDIP-58) questionnaire. The general HRQoL was assessed by using the Medical Outcomes 36-Item Short Form Health Survey (SF-36), while depressive disorder screening was assessed by using the Center of Epidemiologic Studies-Depression (CES-D) questionnaire. The SF-36 and CES-D questionnaire were administered before treatment and every 3 months before the next injection for a 2-year period.

Results: A total of 20 CD patients were enrolled from January 2013 to December 2015. CDIP-58 showed a significant improvement after long-term injections of Abo-BTX A in all domains $(P<0.001)$. However, only vitality domain of SF-36, which assessed general HRQoL, showed a significant improvement after long-term injections $(P=0.037)$. There was no prevalence of depressive disorder in all patients (CES-D score $<20)$ in this study.

Conclusion: The Abo-BTX A injections at 3-month intervals over a 2-year period improved the CDIP-58 scores, which assess disease-specific HRQoL, as well as an increased vitality domain of general HRQoL. No patient suffered from depression in this study.

Keywords: cervical dystonia, abobotulinum toxin A, health-related quality of life, depressive disorder, 36-Item Short Form Health Survey, Cervical Dystonia Impact Profile-58 questionnaire

\section{Introduction}

Patients with cervical dystonia (CD), the most common abnormal movement disorder of head and neck, often suffer from twisting, distress, tremor, distortions, and severe pain in the neck muscles, possibly resulting in depression in such patients suffering from long-term illness. ${ }^{3-7}$ A previous study in Thai patients suggests that torticollis (horizontal turning) of the neck is the most common type, followed by laterocollis (lateral flexion or tilt of the neck), retrocollis (posterior extension of the neck), and anterocollis (forward flexion of the neck). ${ }^{1,2}$ The worldwide incidence rate of CD is 0.80 per 100,000 person-years, and is predominantly observed in female patients. ${ }^{8}$ In a
Correspondence: Subsai Kongsaengdao Division of Neurology, Department of Medicine, 2 Rajavithi Hospital (Victory Monument), Ratchathewi Road,

Bangkok 10400, Thailand

Tel +6623542823

Fax +66 23545477

Email skhongsa@gmail.com
Neuropsychiatric Disease and Treatment 2018:14 I| |9-II24

1119

Dovepress f in $\mathbf{0}$

http://dx.doi.org/1 0.21477NDTS152252 (c) (1) (-) 2018 Kongsaengdao et al. This work is published and licensed by Dove Medical Press Limited. The full terms of this license are available at https://www.dovepress.com/terms.php (c) $\mathrm{BY}$ and incorporate the Creative Commons Attribution - Non Commercial (unported, v3.0) License (http://creativecommons.org/licenses/by-nc/3.0/). By accessing the work you hereby accept the Terms. Non-commercial uses of the work are permitted without any further permission from Dove Medical Press Limited, provided the work is properly attributed. For permission for commercial use of this work, please see paragraphs 4.2 and 5 of our Terms (https://www.dovepress.com/terms.php). 
European study, an estimated prevalence rate of adult-onset focal dystonia was 5.7 per 100,000 persons, while its prevalence rate in Thailand, primarily diagnosed as CD, was $\sim 13.6$ per 100,000 person-years and is predominantly found in females, especially when the patients are in their fourth to fifth decade of life. ${ }^{2}$

Four botulinum toxins (BTXs) have been approved by the US Food and Drug Administration for cervical dystonia: onabotulinum toxin A (Ona-BTX A), abobotulinum toxin A (Abo-BTX A), incabotulinum toxin A, and rimabotulinum toxin $\mathrm{B}$. Additionally, several guidelines recommend them as a standard treatment for CD. Since botulinum toxin A (BTX A) has the best efficacy in the treatment of CD and is able to improve the quality of life, ${ }^{3,9-20}$ both the European Federation of Neurological Societies (EFNS) and the American Association of Neurology (AAN) have categorized BTX A in the level A recommendations and suggest it as firstline treatment. ${ }^{13,21,22}$ In the past, numerous oral medications, including clonazepam, anticholinergics, baclofen, levodopa, tizanidine, gabapentin, and pregabalin, were used in the treatment of CD. ${ }^{2}$ But now, botulinum toxin therapy is the first-line therapy and oral medications are now only infrequently used. Although there were studies of Ona-BTX A ${ }^{23}$ and Abo-BTX $\mathrm{A}^{24}$ in $\mathrm{CD}$ patients, which led to the medication reimbursement policy of Thailand, none of them evaluated health-related quality of life (HRQoL) after the treatment.

In addition to an efficacy of treatment, it is necessary to accurately evaluate the treatment outcomes in terms of the HRQoL for those CD patients..$^{1,2,9,19,23,25-27}$ It is known that as the physical condition improves, the HRQoL improves in CD patients, which is possibly related to the improvement of vision during reading and writing, social embarrassment, pain, depression, and anxiety. . $2,9,19,23,25-27$

Only a few studies have evaluated the QoL of CD patients after treatment with Ona-BTX A and Abo-BTX. One study, in which $C D$ patients were treated with a single injection of 30-300 units of Neu-BTX A, illustrated a significant decrease in CD symptoms by using the Toronto Western Spasmodic Torticollis Rating scale. ${ }^{2}$ Another study also suggested that a 3-month fixed dose of 50 units of Neu-BTX A injections was efficacious in the treatment of such patients when measured by the Cervical Dystonia Impact Profile (CDIP-58) and Cervical Dystonia Questionnaire -24 items (CDQ-24) questionnaires. ${ }^{1}$ Unfortunately, these short-term studies did not show improvement of general HRQoL measured by the 36-Item Short-Form Health Survey (SF-36). ${ }^{1,2}$ Additionally, the remaining studies did not evaluate the quality of life. ${ }^{23}$ Consequently, a longterm study assessing the QoL of CD patients treated with Ona-BTX A and Abo-BTX A may be beneficial.
The aim of the present study was to evaluate both the disease-specific and general HRQoL after eight injections of Abo-BTX A over 2 years in Thai CD patients.

\section{Patients and methods}

This was a 2-year prospective open-label study of the QoL of CD patients treated with Abo-BTX A injections, which is an extension of a previous study. ${ }^{1}$ This study was carried out between January 2013 and December 2015 at the Department of Medical Services, Rajavithi Hospital, Public Health Ministry, Bangkok, Thailand. The study design followed the Declaration of Helsinki and International Conference on Harmonization/Good Clinical Practice Guidelines. The protocol and all amendments were approved by the Ethics Committee of Rajavithi Hospital. All subjects provided a written informed consent before commencing the study protocol.

All adult patients aged between 18 and 80 years, meeting and fulfilling the diagnostic criteria for primary $\mathrm{CD}$, having normal consciousness, understanding the HRQoL questionnaires, and having good communication and understanding of the Thai language were included in this study. The patients who were potentially pregnant or lactating mothers were excluded. Patients who had other medical conditions that possibly affected the present trial evaluations, such as bleeding abnormalities, arthritis and heart disease, other neurological diseases and psychiatric disorders, except depressive disorder, and history of allergy to BTX A, were also excluded.

\section{Study medication}

Abo-BTX A, which was supplied as a freeze-dried powder, was diluted in normal saline and used within 2 hours of preparation. All enrolled patients received intramuscular injections of 250 units of Abo-BTX A in the following neck muscles: sternocleidomastoid, trapezius, and splenius capitis muscles at the opposing side. Each patient was assessed for agonist/ antagonist spasm of the sternocleidomastoid, trapezius, and splenius capitis muscles to determine the site of injection. A total of 500 units of Abo-BTX A was resuspended in $6.0 \mathrm{~mL}$ of normal saline, resulting in a final concentration of $\sim 83.33$ units of Abo-BTX A per $1.0 \mathrm{~mL}$ of solution. Each patient was injected with $20.83-41.66$ units $(0.25-0.5 \mathrm{~mL})$ into each affected site of muscles by using $29 \mathrm{G}$ insulin needles. However, if each muscle had several affected sites, then the total Abo-BTX A dosage was 250 units per injection.

\section{Assessments}

All patients had a complete history and physical examination, and completed the questionnaires. 
All questionnaires were thoroughly explained for all patients. The primary outcome was a change in the CDIP-58 score from pre-treatment to 2 years after eight injections of Abo-BTX A, and the secondary end points were changes in the mean score of SF-36 and Center of Epidemiologic Studies-Depression (CES-D) score.

\section{Efficacy measurement}

\section{The disease-specific HRQoL questionnaire}

The CDIP-58, a validated patient-based and the disease-specific HRQoL scale for health outcomes of patients with $\mathrm{CD}$, is composed of eight health dimension subscales, including head and neck symptoms, pain and discomfort, upper limb activities, walking, sleep, annoyance, mood, and psychosocial functioning. ${ }^{14,17}$ Proven to have good reliability, CDIP-58 is commonly applied for measuring health impacts of patients with CD. ${ }^{12}$ Additionally, the Thai version of CDIP-58, comparing with the original CDIP-58, has been examined for its consistency with Cronbach's alpha $>0.7 .{ }^{1}$ It, therefore, was used to evaluate the HRQoL at pre-treatment and 2 years post-treatment after eight injections of Abo-BTX A.

\section{The general HRQoL questionnaire}

To evaluate the general HRQoL, the SF-36 scale was used. This is a 36-item questionnaire and comprises eight domains: physical functioning (PF), role limitations due to physical health (RP), role limitations due to emotional problems (RE), vitality (VT), mental health (MH), social functioning (SF), bodily pain (BP), and general health (GH). A half of the questions for RE, VT, MH, and SF domains assessed the mental aspect, while PF, RP, and BP domains evaluated the physical health aspect of the CD patients. The Thai version of SF-36 has been validated and tested for reliability in CD patients. ${ }^{1}$

\section{Depression screening questionnaire}

CES-D questionnaire, a short self-report scale, was assigned to identify depressive symptoms for the general population in relation to major or clinical depression. A total of 20 questionnaire items, the CES-D was categorized into six subscales reflecting the major symptoms of depression: depressed mood, feelings of guilt, worthlessness and helplessness, psychomotor retardation, loss of appetite, and sleep difficulties..$^{28,29} \mathrm{The}$ CES-D score ranges from 0 to 3 for each item $(0=$ rarely or none of the time, $1=$ some or little of the time, $2=$ moderately or much of the time, $3=$ most or almost all the time), and therefore the sum of its scores ranges from 0 to 60 , with higher scores demonstrating greater depressive symptoms. The cutoff scores of 20 or more (sensitivity $=79 \%$ and specificity $80 \%$ ) can determine individuals with a risk of clinical depression. Similarly, a Thai version of CES-D has been validated and tested for reliability in the Thai people. ${ }^{30}$

Both SF-36 and CES-D scales were used to evaluate patients at pre-treatment and every 3 months until the next injection for a period of 2 years (Figure 1).

\section{Statistical analysis}

Basic characteristic data were analyzed by using the descriptive statistical analysis. The mean scores (standard deviation [SD]) of CDIP-58, at the baseline and 2 years post-treatment, were compared by using the Wilcoxon's signed-rank test. The mean scores (SD) of SF-36 and CES-D were compared by using the Friedman test (K-related) that compared the nine related samples of data set (unordered treatment). All data were analyzed by using the $\mathrm{Cytel}^{\circledR}{ }^{\circledR}$ Studio ${ }^{\circledR}$ (license no 2060107) software package. All statistical tests were twotailed with a significance level of $\alpha=0.05$.

\section{Results}

A total of 13 females and 7 males, ranging from 26 to 77 years (mean $[\mathrm{SD}]=56.8[12.5]$ years) were eligible to be included in the study. All the included patients participated in the analysis. The mean duration of symptoms in the included patients was 7.0 years ( $2-14$ years). Of the 20 patients, 16 had torticollis, 2 had laterocollis, 1 had anterocollis, and 1 had retrocollis. The mean numbers of previous BTX A injections received

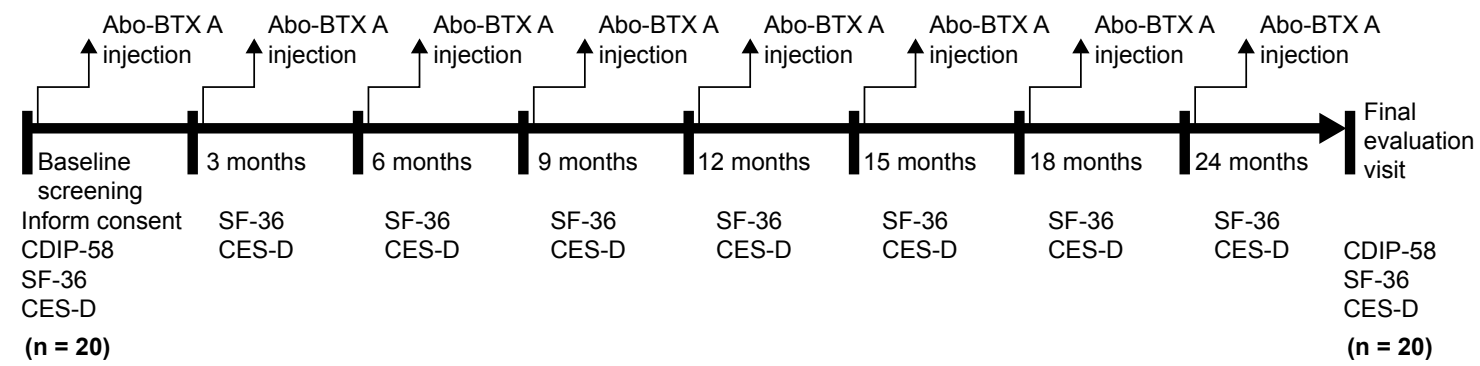

Figure I Schematic diagram showing progression of 20 subjects from baseline screening.

Abbreviations: Abo-BTX A, abobotulinum toxin A; CDIP-58, Cervical Dystonia Impact Profile-58; SF-36, 36-Item Short Form Health Survey; CES-D, Center for Epidemiologic Studies-Depression. 
Table I Demographic and baseline clinical characteristics of patients with cervical dystonia

\begin{tabular}{ll}
\hline Demographics & \\
\hline $\begin{array}{l}\text { Number } \\
\text { Gender, } \mathrm{n}(\%)\end{array}$ & 20 \\
$\quad$ Female & $13(65)$ \\
$\quad$ Male & $7(35)$ \\
Age (years), mean (SD) & $56.8(12.5)$ \\
Disease duration (years), mean (SD) & $7.0(3.1)$ \\
Type of cervical dystonia, $\mathrm{n}(\%)$ & \\
$\quad$ Torticollis & $16(80)$ \\
$\quad$ Laterocollis & $2(10)$ \\
Anterocollis & $\mathrm{I}(5)$ \\
$\quad$ Retrocollis & $\mathrm{I}(5)$ \\
BTX injection dosage (unit per injection time), mean (SD) & $250.0(0.0)$ \\
Previous BTX injection time, mean (SD) & $\mathrm{I} 5.85(4.95)$ \\
\hline Ab
\end{tabular}

Abbreviations: BTX, botulinum toxin; SD, standard deviation.

per patient were $15.85 \pm 4.95$ injections (9-30 injections). Demographic characteristics have been shown in Table 1.

\section{Primary outcomes}

The disease-specific HRQoL after 2-year treatment After 2 years of Abo-BTX A treatment, the overall mean score of the CDIP-58 scale significantly decreased from the baseline values $(P<0.001)$. Similarly, all eight dimensions of the CDIP-58, including head and neck symptoms, pain and discomfort, upper limb activities, walking, sleep, annoyance, mood, and psychosocial functioning, were also significantly improved from the baseline values $(P<0.001)$ (Table 2$)$.

\section{Secondary outcomes}

\section{The general HRQoL after 2-year treatment}

After 2 years of Abo-BTX A treatment, mean scores of SF-36 including four physical components (physical functioning, role limitations due to physical health, bodily pain, and general health) which were assessed at 3-month intervals were not significantly different from the baseline values ( $P=0.880,0.953,0.295$, and 0.298 , respectively). Similarly, mean scores of SF-36 including three mental components (role limitations due to emotional problems, mental health, and social functioning) which were also assessed at 3-month intervals were not significantly different from the baseline values ( $P=0.925,0.993$, and 0.219 , respectively). However, the vitality domain in mental components was significantly increased from the baseline score $(P=0.037)$.

\section{The CES-D scores after 2-year treatment}

Even though all of the CD patients seemed to be distressed from $\mathrm{CD}$, there was no depression in all patients during the pre- and post-treatment based on the CES-D cutoff scores of 20 or more for depressive disorder. According to the
Table 2 Clinical score before (week 0 ) and after ( 2 years) treatment measured by CDIP-58, SF-36, and CES-D (values are given as mean [SD])

\begin{tabular}{|c|c|c|c|}
\hline Questionnaires & $\begin{array}{l}\text { Score at } \\
\text { week } 0 \\
\text { (baseline), } \\
\text { mean (SD) }\end{array}$ & $\begin{array}{l}\text { Score at } \\
2 \text { years, } \\
\text { mean (SD) }\end{array}$ & $P$-value \\
\hline \multicolumn{4}{|l|}{ CDIP-58 } \\
\hline $\begin{array}{l}\text { Head and neck symptoms } \\
\text { (6 items) }\end{array}$ & I5.6 (4.5) & $8.9(1.8)$ & $<0.001$ \\
\hline Pain and discomfort (5 items) & $9.6(3.3)$ & $6.7(1.6)$ & $<0.001$ \\
\hline Upper limb activity (9 items) & $21.5(3.9)$ & $13.4(2.5)$ & $<0.001$ \\
\hline Walking ( 9 items) & $24.7(7.9)$ & $15.7(2.3)$ & $<0.001$ \\
\hline Sleep (4 items) & $10.7(1.9)$ & $6.5(1.5)$ & $<0.001$ \\
\hline Annoyance (8 items) & $23.3(5.8)$ & $14.0(2.3)$ & $<0.001$ \\
\hline Mood (7 items) & $20.0(3.5)$ & I2.I (2.5) & $<0.001$ \\
\hline $\begin{array}{l}\text { Psychosocial functioning } \\
\text { (10 items) }\end{array}$ & $28.7(8.9)$ & I6.I (3.9) & $<0.001$ \\
\hline \multicolumn{4}{|l|}{ SF-36 } \\
\hline Physical functioning (PF) & $75.8(26.2)$ & $59.8(25.3)$ & 0.880 \\
\hline $\begin{array}{l}\text { Role limitations due to } \\
\text { physical health (RP) }\end{array}$ & $63.8(43.3)$ & $42.5(43.8)$ & 0.953 \\
\hline $\begin{array}{l}\text { Role limitations due to } \\
\text { emotional problems (RE) }\end{array}$ & $60.0(50.3)$ & $45.0(47.5)$ & 0.925 \\
\hline Vitality (VT) & $52.0(11.5)$ & $59.5(11.5)$ & $0.037^{*}$ \\
\hline Mental health (MH) & $62.0(9.6)$ & $60.8(11.0)$ & 0.993 \\
\hline Social functioning (SF) & $7.1(10.6)$ & $20.5(25.6)$ & 0.219 \\
\hline Bodily pain (BP) & $28.8(20.7)$ & $43.8(21.7)$ & 0.295 \\
\hline General health $(\mathrm{GH})$ & $42.3(11.8)$ & $46.5(17.3)$ & 0.298 \\
\hline CES-D & $18.9(7.0)$ & $15.9(4.5)$ & 0.260 \\
\hline
\end{tabular}

Note: $* P<0.05$.

Abbreviations: CDIP-58, Cervical Dystonia Impact Profile-58; SF-36, 36-Item Short Form Health Survey; SD, standard deviation; CES-D, Center for Epidemiologic Studies-Depression.

sequential analysis, the trend of the CES-D score reduction was noted without statistical significance (Figure 2).

\section{Discussion}

According to the present study in Thai CD patients, the long-term treatment with Abo-BTX A could improve the disease-specific HRQoL, measured by the CDIP-58 scale. Unfortunately, such a long-term treatment may not improve the general HRQoL, measured by the SF-36, except for the vitality domain.

Previous evidence has indicated that BTX A is efficacious in the treatment of CD by using Toronto Western Spasmodic Torticollis Rating Scale (TWSTRS) questionnaire;, ${ }^{2,9,27}$ however, there have been few studies that evaluated the QoL after undergoing treatment in these patients by various types of $\mathrm{CD}$ and various doses of BTX A, as well as various durations of treatment, particularly in a long-term treatment. ${ }^{1,26}$ To our knowledge, this is the first study to evaluate the QoL as well as depression in the course of long-term treatment with low doses of Abo-BTX A. 


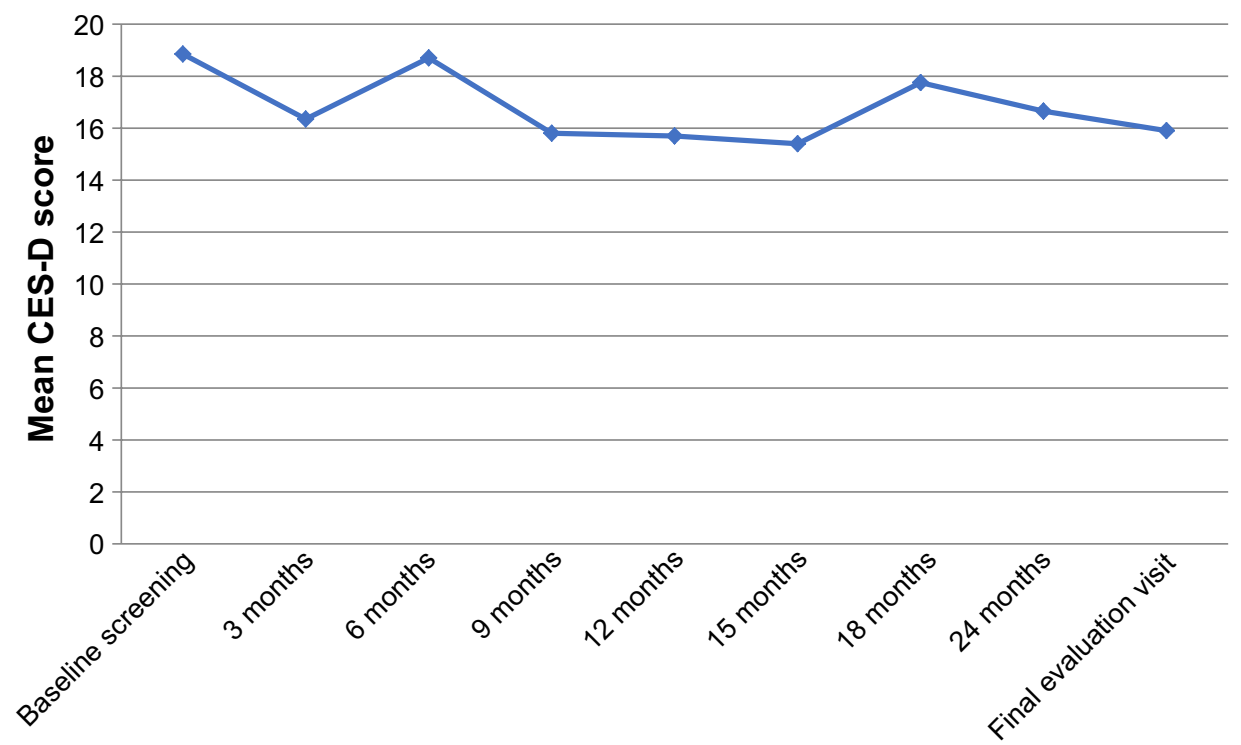

3-Month intervals from baseline screening

Figure 2 Mean CES-D score assessment at 3-month intervals.

Abbreviation: CES-D, Center for Epidemiologic Studies-Depression.

Previous short-term studies have suggested that the BTX A treatment is able to improve the disease-specific HRQoL, but not the general HRQoL. Jagota et $\mathrm{al}^{2}$ suggested that a single Neu-BTX A injection treatment in patients could significantly improve CD symptoms, measured by the TWSTRS (both severity and total scores) and borderline significantly improve in HRQoL measured by CDQ-24. Similarly, Kongsaengdao et al indicated that three injections with 50 units of Neu-BTX A injection could significantly improve the disease-specific HRQoL, measured by the CDIP-58 and CDQ-24 questionnaires, but not general HRQoL, measured by EuroQoL five dimensions (EDQ-5) and SF-36. ${ }^{1}$ In an another prospective, open-label study, a single injection of 500 units of Abo-BTX A in 516 patients also showed an improvement in the disease-specific HRQoL, measured by the CDQ-24. ${ }^{25}$ The findings of the present study have indicated that the improvements in the disease-specific HRQoL not only occurred in the short-term treatment but also in the long-term treatment with BTX A in CD patients.

Previous studies showed that depression, measured by the Montgomery-Asberg Depression Rating Scale, was found in $47.5 \%$ of the CD patients. ${ }^{26-28}$ An improvement was observed in these patients after receiving a single BTX A injection. Additionally, depression is a predictor of poor HRQoL. Since depression, as rated by the CES-D, was not observed in the CD patients of the present study, improvement in the depressive symptoms could not be found after the BTX A treatments.
There were some limitations in this study. Firstly, since the sample size was small, we were cautious to interpret the outcomes. These results must be reviewed with caution due to the placebo effect and the lack of a control group in this study. Additionally, these findings are also subject to considerable selection bias because only patients who were already responding to BTX therapy were included in this study. BTXs are not interchangeable; therefore, the findings of this study are specific to Abo-BTX A and are not generalizable to any other BTX. A further long-term and well-defined study is warranted to validate these findings.

\section{Conclusion}

The long-term treatment with Abo-BTX A could improve the disease-specific HRQoL. Unfortunately, such a longterm treatment may not improve all domains of the general HRQoL. Further well-defined studies should be conducted to evaluate these outcomes.

\section{Acknowledgments}

We thank Rajavithi Hospital, Department of Medical Services, Ministry of Public Health, Thailand, for the grant support. Also, the authors wish to thank all the patients who participated in the present study.

\section{Author contributions}

All authors contributed toward data analysis, drafting, and critically revising the paper and agreed to be accountable for all aspects of the work. 


\section{Disclosure}

$\mathrm{BM}$ has received honoraria and/or travel reimbursement from Lundbeck, Pfizer, and Servier. NM has received travel reimbursement from Lundbeck and Pfizer. SK reports no conflicts of interest in this work. Narong Maneeton and Benchalak Maneeton are husband and wife. Benchalak Maneeton is Subsai Kongsaengdao's sister.

\section{References}

1. Kongsaengdao S, Maneeton B, Maneeton N. Quality of life in cervical dystonia after treatment with botulinum toxin A: a 24-week prospective study. Neuropsychiat Dis Treat. 2017;13:127-132.

2. Jagota P, Kaewwilai L, Boonrod N, et al. Impact of neu-botulinumtoxinA on the severity and quality of life of cervical dystonia patients. Tremor Other Hyperkinet Move. 2016;6:407.

3. Jankovic J. Treatment of dystonia. Lancet Neurol. 2006;5(10): 864-872.

4. Comella CL, Thompson PD. Treatment of cervical dystonia with botulinum toxins. Eur J Neurol. 2006;13(Suppl 1):16-20.

5. Chan J, Brin MF, Fahn S. Idiopathic cervical dystonia: clinical characteristics. Mov Disord. 1991;6(2):119-126.

6. de Carvalho Aguiar PM, Ozelius LJ. Classification and genetics of dystonia. Lancet Neurol. 2002;1(5):316-325.

7. Bressman SB, Greene PE. Dystonia. Curr Treat Options Neurol. 2000; 2(3):275-285.

8. Epidemiological Study of Dystonia in Europe Collaborative Group. A prevalence study of primary dystonia in eight European countries. J Neurol. 2000;247(10):787-792.

9. Slawek J, Friedman A, Potulska A, et al. Factors affecting the healthrelated quality of life of patients with cervical dystonia and the impact of botulinum toxin type A injections. Funct Neurol. 2007;22(2):95-100.

10. Costa J, Espirito-Santo C, Borges A, Ferreira JJ, Coelho M, Sampaio C. Botulinum toxin type A versus anticholinergics for cervical dystonia. Cochrane Database Syst Rev. 2005;(1):CD004312.

11. Walker FO. Botulinum toxin therapy for cervical dystonia. Phys Med Rehabili Clin N Am. 2003;14(4):749-766, vi.

12. Simpson DM, Blitzer A, Brashear A, et al. Assessment: botulinum neurotoxin for the treatment of movement disorders (an evidence-based review): report of the Therapeutics and Technology Assessment Subcommittee of the American Academy of Neurology. Neurology. 2008; 70(19):1699-1706.

13. Ferreira JJ, Costa J, Coelho M, Sampaio C. The management of cervical dystonia. Expert Opin Pharmacother. 2007;8(2):129-140.

14. Brashear A. The botulinum toxins in the treatment of cervical dystonia. Sem Neurol. 2001;21(1):85-90.

15. Cano SJ, Hobart JC, Edwards M, et al. CDIP-58 can measure the impact of botulinum toxin treatment in cervical dystonia. Neurology. 2006;67(12):2230-2232.
16. Brans JW, Lindeboom R, Aramideh M, Speelman JD. Long-term effect of botulinum toxin on impairment and functional health in cervical dystonia. Neurology. 1998;50(5):1461-1463.

17. Pekmezovic T, Svetel M, Ivanovic N, et al. Quality of life in patients with focal dystonia. Clin Neurol Neurosurg. 2009;111(2):161-164.

18. Hakkinen A, Ylinen J, Rinta-Keturi M, Talvitie U, Kautiainen H, Rissanen A. Decreased neck muscle strength is highly associated with pain in cervical dystonia patients treated with botulinum toxin injections. Arch Phy Med Rehab. 2004;85(10):1684-1688.

19. Hilker R, Schischniaschvili M, Ghaemi M, Jacobs A, Rudolf J. Health related quality of life is improved by botulinum neurotoxin type A in long term treated patients with focal dystonia. $J$ Neurol Neurosurg Psychiatry. 2001;71(2):193-199.

20. Wenzel T, Schnider P, Wimmer A, Steinhoff N, Moraru E, Auff E. Psychiatric comorbidity in patients with spasmodic torticollis. J Psychosom Res. 1998;44(6):687-690.

21. Albanese A, Asmus F, Bhatia KP, et al. EFNS guidelines on diagnosis and treatment of primary dystonias. Eur J Neurol. 2011;18(1):5-18.

22. Albanese A, Barnes MP, Bhatia KP, et al. A systematic review on the diagnosis and treatment of primary (idiopathic) dystonia and dystonia plus syndromes: report of an EFNS/MDS-ES Task Force. Eur J Neurol. 2006;13(5):433-444.

23. Poungvarin N, Viriyavejakul A. Botulinum A toxin treatment in spasmodic torticollis: report of 56 patients. J Med Assoc Thai. 1994; 77(9):464-470.

24. Bhidayasiri R. Treatment of complex cervical dystonia with botulinum toxin: involvement of deep-cervical muscles may contribute to suboptimal responses. Parkinsonism Relat Disord. 2011;17(Suppl 1): S20-S24.

25. Hefter H, Benecke R, Erbguth F, Jost W, Reichel G, Wissel J. An openlabel cohort study of the improvement of quality of life and pain in de novo cervical dystonia patients after injections with $500 \mathrm{U}$ botulinum toxin A (Dysport). BMJ Open. 2013;3(4):e001853.

26. Skogseid IM, Malt UF, Roislien J, Kerty E. Determinants and status of quality of life after long-term botulinum toxin therapy for cervical dystonia. Eur J Nurol. 2007;14(10):1129-1137.

27. Mordin M, Masaquel C, Abbott C, Copley-Merriman C. Factors affecting the health-related quality of life of patients with cervical dystonia and impact of treatment with abobotulinum toxin A (Dysport): results from a randomised, double-blind, placebo-controlled study. BMJ Open. 2014;4(10):e005150.

28. Radloff LS. A self-report depression scale for research in the general population. Appl Psychol Meas. 1977;1:385-401.

29. Blank K, Gruman C, Robison JT. Case-finding for depression in elderly people: balancing ease of administration with validity in varied treatment settings. J Gerontol A Biol Sci Med Sci. 2004;59(4):378-384.

30. Trangkasombat U, Likanapichitkul D. The Children's Depression Inventory as a screen for depression in Thai children. $J$ Med Assoc Thai. 1997;80(8):491-499.
Neuropsychiatric Disease and Treatment

\section{Publish your work in this journal}

Neuropsychiatric Disease and Treatment is an international, peerreviewed journal of clinical therapeutics and pharmacology focusing on concise rapid reporting of clinical or pre-clinical studies on a range of neuropsychiatric and neurological disorders. This journal is indexed on PubMed Central, the 'PsycINFO' database and CAS,

\section{Dovepress}

and is the official journal of The International Neuropsychiatric Association (INA). The manuscript management system is completely online and includes a very quick and fair peer-review system, which is all easy to use. Visit http://www.dovepress.com/testimonials.php to read real quotes from published authors. 